\title{
Analysis of 24-hour pulse wave velocity in patients with renal transplantation
}

This article was published in the following Dove Press journal: International Journal of Nephrology and Renovascular Disease 28 June 2013

Number of times this article has been viewed

\author{
Irina E Minyukhina' \\ Kirill S Lipatov' \\ Igor N Posokhov ${ }^{2}$ \\ 'Privolzhsky District Medical \\ Center, Nizhniy Novgorod, Russia; \\ ${ }^{2}$ Hemodynamic Laboratory, Nizhniy \\ Novgorod, Russia
}

Correspondence: Irina E Minyukhina Privolzhsky District Medical Center, Nizhnevolzhskaya Naberezhnaya 2, 60300 I, Nizhniy Novgorod, Russia

Tel +7 9030553036

Fax $+783|296| 4 \mid 5$

Emailminyukhina@24h-monitoring.com
Abstract: The aim of our study was to assess the feasibility of using an approach to 24-hour pulse wave velocity (PWV) analysis similar to ambulatory blood pressure monitoring analysis in the management of patients with renal transplantation. Overall, 41 patients aged between 18 and 55 years who had end-stage renal disease resulting from glomerulopathy were recruited from the kidney transplant waiting list. All the measurements were performed before kidney transplantation and at 1 and 20 weeks after transplantation. The Pulse Time Index of Norm (PTIN) was calculated with the Vasotens ${ }^{\circledR}$ technology for the estimation of the 24-hour PWV, defined as the percentage of the 24-hour period during which the PWV does not exceed $10 \mathrm{~m} / \mathrm{second}$. Before kidney transplantation, the mean PTIN in the whole group was 56.3 (standard deviation, 18.4). Then, a week after the renal transplantation, a decrease in the PTIN was observed in most cases, going to 27.6 (standard deviation, 11.1). After 20 weeks, the mean PTIN in the whole group increased again to 52.0 (standard deviation, 23.6). In our study, we found that the persistence of arterial stiffness disturbances after kidney transplantation appears to be relatively predictable. We determined the cutoff value of PTIN that could predict the two states of PTIN: a state of improvement or a state of decline/without change. The cutoff value of PTIN at $45 \%$ had a sensitivity of $69 \%$, specificity of $76 \%$, and area under the curve of 0.65 . The analysis of variance showed that in the group with an initial PTIN of $45 \%$ or higher, the PTIN in the remote period after transplantation changed significantly $(P<0.05)$, whereas in the group with an initial PTIN lower than $45 \%$, there were no significant changes. Thus, the analysis of 24 -hour pulse wave velocity in the management of patients with renal transplantation using PTIN is feasible.

Keywords: renal transplantation, pulse wave velocity, 24-hour monitoring, PTIN

\section{Introduction}

The question of structural and mechanical alterations of the arterial wall in the case of renal transplantation has not yet been completely resolved. An insufficiency of endogenous regulators of calcium and phosphate is well known to be a significant factor affecting extraosseous calcifications. ${ }^{1}$ In dialysis patients and kidney transplant patients, volume overload and disturbances of calcium and phosphate metabolism add to the atherogenic profile, and these serve as independent risk factors for cardiovascular mortality. ${ }^{2}$ The presence of arterial calcifications was strongly and independently predictive of the outcome in end-stage renal disease (ESRD). ${ }^{3}$ On this basis, estimating the arterial stiffness (AS) in ESRD is of great interest. Measuring the pulse-wave velocity (PWV) is a reliable means of determining the AS.,5

There are several studies of PWV in patients with renal transplantation. ${ }^{6-9}$ Notably, 24-hour PWV analysis has not yet been conducted in adults. Meanwhile, some modern 
devices for ambulatory blood pressure monitoring (ABPM) allow the assessment of some AS indices, and the approach to the analysis of these indices may be quite similar to that of ABPM. ${ }^{10}$ Accordingly, the aim of our study was to assess the feasibility of this approach in the management of patients with renal transplantation.

\section{Methods}

\section{Baseline characteristics}

Overall, 41 patients were recruited from the kidney transplant waiting list of the Privolzhsky District Medical Center in Nizhniy Novgorod, Russia. The inclusion criteria were the following: age between 18 years and 55 years, ESRD resulting from nondiabetic glomerulopathy (glomerular filtration rate $<15 \mathrm{~mL} / \mathrm{min}$ per $1.73 \mathrm{~m}^{2}$ ), and candidate for a first kidney transplant. Patients with a history of prior kidney transplant or who were candidates for a kidney-pancreas transplant were excluded from the study. The additional exclusion criteria were cardiac rhythm disturbances, body mass index higher than $35 \mathrm{~kg} / \mathrm{m}^{2}$, severe dyslipidemia, and unstable clinical presentation. Our study group included 27 (65.8\%) men and had a mean age of 35.2 years, with a mean systolic blood pressure of $134 \mathrm{mmHg}$, mean diastolic blood pressure of $86 \mathrm{mmHg}$, and mean heart rate of 74 beats per minute. All the patients were receiving dialysis at enrollment, including 40 by hemodialysis and one by peritoneal dialysis. Management of patients included the monitoring of calcium and phosphate serum levels and their correction. All measurements were performed before kidney transplantation and at 1 and 20 weeks after transplantation. Approval for the study was obtained from the local research ethics committee, and written informed consent was obtained for each participant.

\section{Vasotens ${ }^{\circledR}$ technology}

The Vasotens ${ }^{\circledR}$ technology is an innovative method used for pulse-wave analysis based on oscillometric blood pressure measurements, using the BPLab (Nizhniy Novgorod, Russia) device for ABPM. ${ }^{11,12}$ The technology was developed by the Petr Telegin Company in Nizhniy Novgorod, Russia. This method involves assessing pulse waves at the brachial artery. The recordings are made using a conventional blood pressure cuff for adults. During the blood pressure measurement, the pressure waveforms in the cuff are registered while performing a step-by-step deflation. The separation and timing of the forward and reflected pulse waves are determined by a special mathematical algorithm. The distance for the PWV equation used by the Vasotens ${ }^{\circledR}$ was measured according to

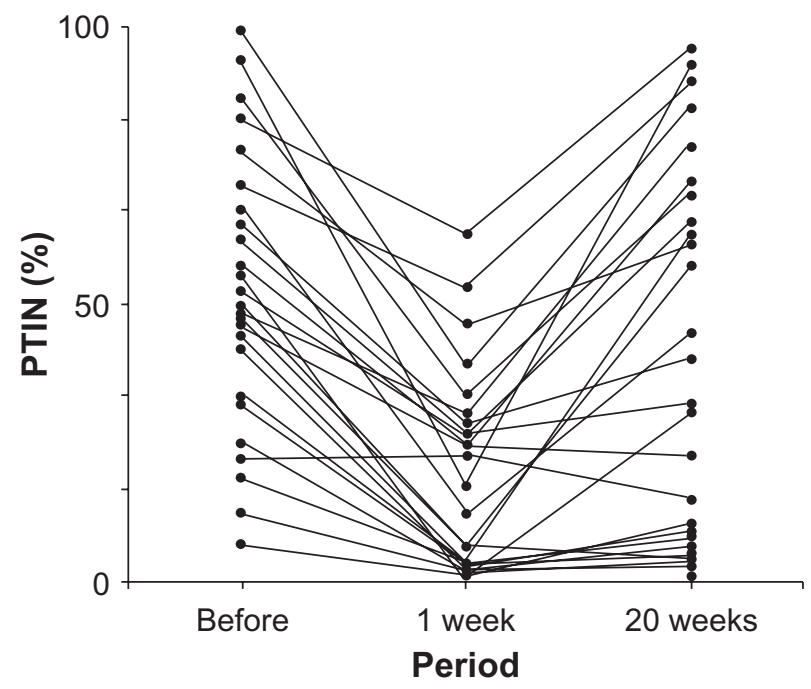

Figure I PTIN in patients before and after renal transplantation. Abbreviation: PTIN, Pulse Time Index of Norm.

the BPLab user's guide requirements. The quality control method consists of a visual assessment of the curves in the Vasotens $^{\circledR}$ clinical report screen.

The Pulse Time Index of Norm (PTIN) is calculated by the Vasotens ${ }^{\circledR}$ for the estimation of the 24-hour PWV. The principle of the PTIN calculation is

$$
\text { PTIN, } \%=\left(T_{1}+T_{2}+\ldots+T_{n}\right) / T_{m} \times 100
$$

where $T_{m}$ is the entire period of monitoring and $T_{1}, T_{2}$, and $\mathrm{T}_{\mathrm{n}}$ represent the periods in which the PWV does not exceed the cut-off value of $10 \mathrm{~m} / \mathrm{second}$.

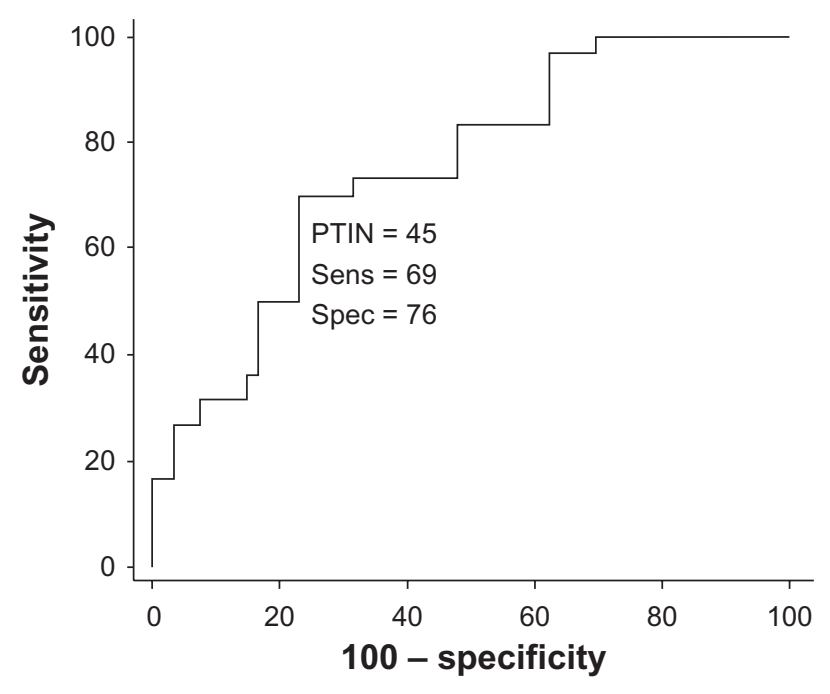

Figure 2 Receiver operating characteristic curve to determine the cut-off value and area under the curve for different PTIN states after transplantation.

Abbreviations: PTIN, Pulse Time Index of Norm; sens, sensitivity; spec, specificity. 
Table I Characteristics of the examined patients

\begin{tabular}{|c|c|c|c|}
\hline & $\begin{array}{l}\text { PTIN before transplantation } \\
\geq 45 \%, n=24\end{array}$ & $\begin{array}{l}\text { PTIN before transplantation } \\
<45 \%, n=17\end{array}$ & $P$ (Mann-Whitney U) \\
\hline Male, n (\%) & $16(66.6)$ & II (64.7) & \\
\hline Age, $m(S D)$ years & $33(9)$ & $38(11)$ & 0.0590 \\
\hline Height, $\mathrm{m}(\mathrm{SD}) \mathrm{cm}$ & $168(12)$ & $168(11)$ & 0.5 \\
\hline Weight, m (SD) kg & $76(6)$ & $75(7)$ & 0.6264 \\
\hline Preoperative dialysis period, $m(S D)$ years & $2.5(0.3)$ & $3.8(3.0)$ & 0.0405 \\
\hline Carotid plaque, $n(\%)$ & $4(16.7)$ & $3(17.6)$ & \\
\hline SBP, $\mathrm{m}(\mathrm{SD}) \mathrm{mmHg}$ & $132(15)$ & $138(16)$ & 0.2270 \\
\hline $\mathrm{DBP}, \mathrm{m}(\mathrm{SD}) \mathrm{mmHg}$ & $86(7)$ & $87(8)$ & 0.9905 \\
\hline Heart rate, $m(S D)$ beats per minute & $74(8)$ & $76(9)$ & 0.4584 \\
\hline Serum calcium, m (SD) mg/dL & $9.3(0.9)$ & $9.2(0.8)$ & 0.7915 \\
\hline Serum phosphorus, $\mathrm{m}(\mathrm{SD}) \mathrm{mg} / \mathrm{dL}$ & $4.9(0.9)$ & $5.1(1.3)$ & 0.5632 \\
\hline
\end{tabular}

Abbreviations: DBP, diastolic blood pressure; PTIN, Pulse Time Index of Norm; SBP, systolic blood pressure; m, mean; SD, standard deviation.

\section{Statistics}

Essentially, all the data are shown as the mean and standard deviation (SD). We used BPStat software, version 05.00.04 (BPLab) to tabulate all the indices of every measured 24-hour waveform automatically. Then, analysis of variance, receiver operating characteristic analysis, and the Mann-Whitney $U$ test were used.

\section{Results}

The PTINs in different periods before and after renal transplantation are illustrated in Figure 1.

As shown in Figure 1, before kidney transplantation, there was a wide range of PTIN values. The mean PTIN in the whole group was 56.3 (SD, 18.4). As our analysis showed, this value did not depend on the duration of the history of the disease or the time of the interdialysis period at which the monitoring was performed.

Then, a week after the renal transplantation, we observed a decrease in the PTIN in most cases. The mean PTIN in the whole group at this period was 27.6 (SD, 11.1). After 20 weeks, the mean PTIN in the whole group increased again to 52.0 (SD, 23.6), but the detailed analysis showed that those patients who had a higher value of PTIN before transplantation had a higher increase at this time. Using the receiver operating characteristic curve, we determined the cutoff value of PTIN that could predict the two PTIN states: a state of improvement or a state of decline/without change (Figure 2). The cutoff value of PTIN at $45 \%$ had a sensitivity of $69 \%$, specificity of $76 \%$, and area under the curve of 0.65 to predict these states. For the detailed baseline characteristics of the patient groups separated according to this cut-off point, please see Table 1.

As shown in Table 1, there was no significant difference between the groups for almost all characteristics except the PTIN. The difference in preoperative dialysis period $(P=0.0405)$ and the tendency toward a difference in age $(P=0.0590)$ should be noted. The PTIN at different periods before and after renal transplantation in the groups with PTIN of $45 \%$ or higher or less $45 \%$ is illustrated in Figure 3.
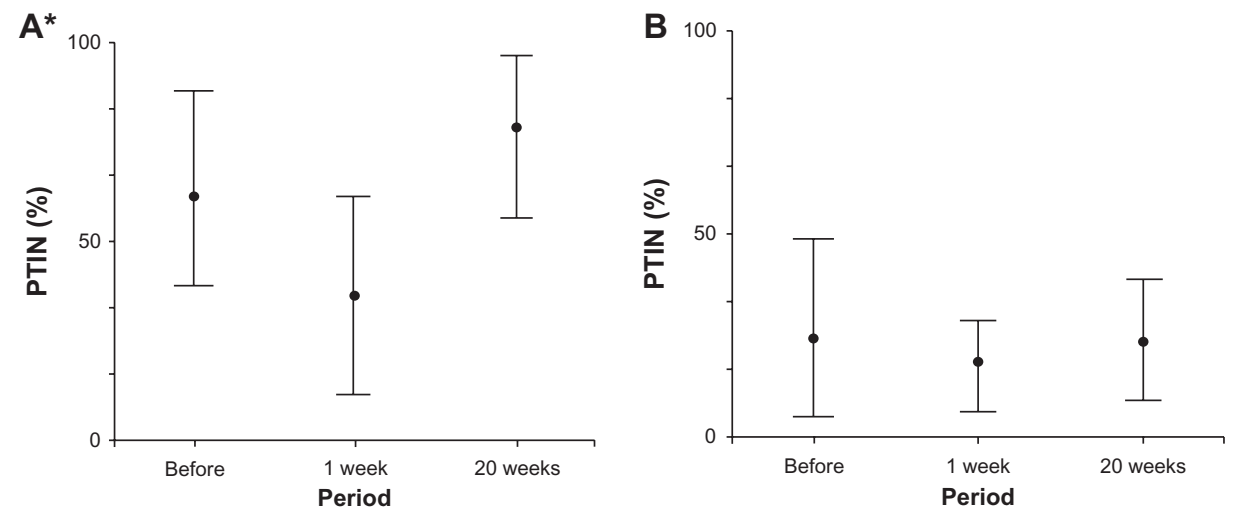

Figure 3 The PTIN in the patients before and after renal transplantation.

Notes: $* P<0.05$ (analysis of variance). (A) The group with PTIN before transplantation $\geq 45 \%$. (B) The group with PTIN $<45 \%$.

Abbreviation: PTIN, Pulse Time Index of Norm. 
The analysis of variance showed that in the first group, the PTIN changed significantly $(P<0.05)$, whereas in the second group, the PTIN was not significantly different. The effect of renal transplantation on blood pressure (Table 2) was similar to the effect on the PTIN.

\section{Discussion}

Some authors have noted an improvement in the AS after kidney transplantation..$^{6-8} \mathrm{~A}$ number of studies have shown that after kidney transplantation, the disturbances in calcium and phosphate metabolism improve in general, but the media calcification, structural alterations of the arterial wall, and disturbed mechanical vessel wall properties persist., ${ }^{9}{ }^{13-15}$

In our study, we found that the persistence of these disturbances after kidney transplantation appears to be relatively predictable: there are clear differences in the clinical conditions of patients who develop an excess in the PWV over the cutoff value for either a small or large percentage of the monitoring period. If PTIN is $45 \%$ or higher before kidney transplantation, there appears to be a good chance that the PTIN will improve in the remote period after transplantation. This improvement is particularly important for the management in the initial period after implantation, when increased damage to the arterial wall, resulting in a decreased PTIN in most patients, is observed. It is known that the prevalence of postoperative hypertension in patients with renal transplantation is high, and this is one reason for an aggressive therapeutic approach by physicians, reflected by administering more antihypertensive medications. ${ }^{16}$ The PTIN seems to give us an opportunity to optimize this approach.

Regarding the influence of hemodialysis on the variability of the PWV, a study in which the measurements were performed immediately before (pre) and 1 hour after (post) the end of each dialysis session should be noted. Cyclic intradialysis changes in the PWV were similar during the three dialysis sessions; as a consequence, all postdialytic PWV values were lower with respect to the predialytic levels. ${ }^{17}$

Table 2 The effect of renal transplantation on blood pressure in separated groups of patients, $\mathrm{m}(\mathrm{SD}) \mathrm{mmHg}$

\begin{tabular}{|c|c|c|c|c|}
\hline & \multicolumn{2}{|c|}{$\begin{array}{l}\text { PTIN before } \\
\text { transplantation } \\
\geq 45 \%, n=24\end{array}$} & \multicolumn{2}{|c|}{$\begin{array}{l}\text { PTIN before } \\
\text { transplantation } \\
<\mathbf{4 5 \% , n = 1 7}\end{array}$} \\
\hline & Systolic & Diastolic & Systolic & Diastolic \\
\hline Before & $132(15)$ & $86(7)$ & $138(16)$ & $87(8)$ \\
\hline I week & $143(16)$ & 95 (7) & 147 (I7) & 97 (8) \\
\hline 20 weeks & $136(15)$ & $86(7)$ & 145 (18) & $98(9)$ \\
\hline
\end{tabular}

Abbreviations: PTIN, Pulse Time Index of Norm; m, mean; SD, standard deviation.
As our analysis showed, the PTIN did not depend on the time of the interdialysis period at which the monitoring was performed. In our opinion, this mismatching is a result of the smoothing effect of the nocturnal pattern of PWV in PTIN, which integrates the PWV values over the course of 24 hours.

Thus, the analysis of the 24-hour pulse wave velocity in the management of patients with renal transplantation using PTIN is feasible.

\section{Disclosure}

The authors report no conflicts of interest in this work.

\section{References}

1. Ketteler M, Wanner C, Metzger T, et al. Deficiencies of calciumregulatory proteins in dialysis patients: a novel concept of cardiovascular calcification in uremia. Kidney Int Suppl. 2003;(84):S84-S87.

2. Ketteler M, Bongartz P, Westenfeld R, et al. Association of low fetuin-A (AHSG) concentrations in serum with cardiovascular mortality in patients on dialysis: a cross-sectional study. Lancet. 2003;361(9360): 827-833.

3. Blacher J, Guerin AP, Pannier B, Marchais SJ, London GM. Arterial calcifications, arterial stiffness, and cardiovascular risk in end-stage renal disease. Hypertension. 2001;38(4):938-942.

4. Asmar R, Benetos A, Topouchian J, et al. Assessment of arterial distensibility by automatic pulse wave velocity measurement. Validation and clinical application studies. Hypertension. 1995;26(3):485-490.

5. Salvi P, Lio G, Labat C, Ricci E, Pannier B, Benetos A. Validation of a new non-invasive portable tonometer for determining arterial pressure wave and pulse wave velocity: the PulsePen device. J Hypertens. 2004;22(12):2285-2293.

6. Covic A, Goldsmith DJ, Gusbeth-Tatomir P, Buhaescu I, Covic M. Successful renal transplantation decreases aortic stiffness and increases vascular reactivity in dialysis patients. Transplantation. 2003;76(11): 1573-1577.

7. De Lima JJ, Vieira ML, Viviani LF, et al. Long-term impact of renal transplantation on carotid artery properties and on ventricular hypertrophy in end-stage renal failure patients. Nephrol Dial Transplant. 2002;17(4):645-651.

8. Posadzy-Malaczyñska A, Kosch M, Hausberg M, et al. Arterial distensibility, intima media thickness and pulse wave velocity after renal transplantation and in dialysis normotensive patients. Int Angiol. 2005;24(1):89-94.

9. Zoungas S, Kerr PG, Chadban S, et al. Arterial function after successful renal transplantation. Kidney Int. 2004;65(5):1882-1889.

10. Posokhov IN. Pulse wave velocity 24-hour monitoring with one-site measurements by oscillometry. Med Devices (Auckl). 2016:11-15.

11. Rogoza AN, Kuznetsov AA. Central aortic blood pressure and augmentation index: comparison between Vasotens ${ }^{\circledR}$ and SphygmoCor ${ }^{\circledR}$ technology. Res Rep Clin Cardiol. 2012;3:27-33.

12. Ageenkova OA, Purygina MA. Central aortic blood pressure, augmentation index, and reflected wave transit time: reproducibility and repeatability of data obtained by oscillometry. Vasc Health Risk Manag. 2017:649-656.

13. Barenbrock M, Hausberg M, Kosch M, Kisters K, Hoeks AP, Rahn KH. Effect of hyperparathyroidism on arterial distensibility in renal transplant recipients. Kidney Int. 1998;54(1):210-215.

14. Leskinen Y, Salenius JP, Lehtimäki T, Huhtala H, Saha H. The prevalence of peripheral arterial disease and medial arterial calcification in patients with chronic renal failure: requirements for diagnostics. Am J Kidney Dis. 2002;40(3):472-479. 
15. Safar ME, O'Rourke MF, editors. Arterial stiffness in hypertension. Amsterdam: Elsevier; 2006.

16. Kasiske BL, Anjum S, Shah R, et al. Hypertension after kidney transplantation. Am J Kidney Dis. 2004;43(6):1071-1081.
17. Di Iorio B, Nazzaro P, Cucciniello E, Bellizzi V. Influence of haemodialysis on variability of pulse wave velocity in chronic haemodialysis patients. Nephrol Dial Transplant. 2010;25(5): $1579-1583$.

\section{Publish your work in this journal}

The International Journal of Nephrology and Renovascular Disease is an international, peer-reviewed open-access journal focusing on the pathophysiology of the kidney and vascular supply. Epidemiology, screening, diagnosis, and treatment interventions are covered as well as basic science, biochemical and immunological studies. The journal welcomes original research, clinical studies, reviews \& evaluations, expert opinion and commentary, case reports and extended reports. The manuscript management system is completely online and includes a very quick and fair peerreview system, which is all easy to use. Visit http://www.dovepress.com/ testimonials.php to read real quotes from published authors.

Submit your manuscript here: http://www.dovepress.com/international-journal-of-nephrology-and-renovascular-disease-journal 